Jurnal Ilmiah Matematika dan Pendidikan Matematika (JMP)

Vol. 9 No. 2, Desember 2017, hal. 1-10

ISSN (Cetak) : 2085-1456; ISSN (Online) : 2550-0422; https://jmpunsoed.com/

\title{
PEMETAAN KONTRAKTIF LEMAH MULTIVALUED \\ DI RUANG METRIK PARSIAL
}

\author{
Sagita Charolina Sihombing \\ Fakultas MIPA, Universitas PGRI Palembang \\ Jl. Jend. A. Yani Lrg. Gotong Royong 9/10 Ulu Palembang \\ Sagita.Charolina@yahoo.com
}

\section{Ety Septiati}

Fakultas Keguruan dan Ilmu Pendidikan, Universitas PGRI Palembang Jl. Jend. A. Yani Lrg. Gotong Royong 9/10 Ulu Palembang

\begin{abstract}
In this paper, we study the existence of fixed point of the $\varphi$-weak contraction mapping in the complete partial metric space for multivalued mapping. Distance calculations are performed using Hausdorff metric. The result obtained in this paper is an extension of similar result for single valued mapping.
\end{abstract}

Keywords: Complete partial metric space, fixed point, $\phi$-weakly contractive mapping, Hausdorff metric.

Abstrak. Pada makalah ini akan dikaji eksistensi titik tetap dari pemetaan kontraktif lemah $-\phi$ di ruang metrik parsial lengkap untuk pemetaan multivalued. Perhitungan jarak dilakukan menggunakan metrik Hausdorff. Hasil yang diperoleh pada makalah ini merupakan perluasan dari hasil serupa untuk pemetaan single valued.

Kata Kunci: Ruang metrik parsial lengkap, titik tetap, Pemetaan Kontraktif Lemah $-\phi$, metrik Hausdorff

\section{PENDAHULUAN}

Pemetaan kontraktif $f: X \rightarrow X$ adalah pemetaan yang memenuhi ketaksaman

$$
d(f(x), f(y)) \leq K d(x, y)
$$

pada teorema titik tetap Banach, dengan $x$ dan $y$ adalah elemen di ruang metrik $(X, d)$, dan $K$ adalah konstanta yang mempunyai nilai antara 0 dan 1 . Teorema titik tetap Banach memberikan suatu syarat cukup untuk eksistensi titik tetap dari suatu pemetaan yang didefinisikan pada ruang metrik $(X, d)$. Dalam hal ini titik $c \in X$ merupakan titik tetap dari $f$ apabila $f(c)=c$. 
Pengembangan sifat pemetaan kontraktif telah dilakukan oleh para peneliti untuk menunjukkan eksistensi titik tetap di ruang metrik parsial $(X, p)$, yaitu himpunan tak kosong $X$ yang disertai fungsi metrik parsial $p: X \times X \rightarrow \mathbb{R}^{+}$dengan $x, y, z \in X$ memenuhi kondisi berikut:

(p1). $p(x, x) \leq p(x, y)$

(p2). $x=y$ jika dan hanya jika $p(x, x)=p(x, y)=p(y, y)$

(p3). $p(x, y)=p(y, x)$

(p4). $p(x, y) \leq p(x, z)+p(z, y)-p(z, z)$

Definisi ruang metrik parsial tersebut dapat dilihat pada (Gangopadhyay, dkk., 2013). Bukatin, dkk. (2009) menyebutkan bahwa ruang metrik parsial, yang diperkenalkan pertama kali oleh Matthews (1992), merupakan pengembangan dari ruang metrik. Pengembangan ini didasari oleh permasalahan yang ditemukan dalam ilmu komputer, yaitu dua barisan tak hingga yang sama belum tentu memiliki jarak nol. Bukatin, dkk. juga membuktikan bahwa pemetaan kontraktif pada ruang metrik parsial masih menjamin eksistensi titik tetap. Hubungan antara ruang metrik dengan ruang metrik parsial diberikan dalam lemma berikut.

Lemma 1. [Masiha, dkk., 2013] Jika $(X, p)$ adalah ruang metrik parsial dan fungsi $p^{s}: X \times X \rightarrow[0, \infty)$ didefinisikan oleh

$$
p^{s}(x, y)=2 p(x, y)-p(x, x)-p(y, y), \quad \forall x, y \in X,
$$

maka $p^{s}$ adalah sebuah metrik.

Sementara itu, syarat agar suatu ruang metrik parsial merupakan ruang metrik parsial lengkap diberikan dalam lemma berikut.

Lemma 2. [Kir dan Kiziltunc, 2016] Misalkan $(X, p)$ adalah ruang metrik parsial.

a. Barisan $\left\{x_{n}\right\}$ adalah barisan Cauchy di $(X, p)$ jika dan hanya jika barisan tersebut adalah barisan Cauchy di $\left(X, p^{S}\right)$. 
b. Ruang metrik $(X, p)$ merupakan ruang metrik parsial lengkap jika dan hanya jika $\left(X, p^{s}\right)$ merupakan ruang metrik parsial lengkap.

Selanjutnya, Altun, dkk. (2010) membuktikan sifat titik tetap dalam pemetaan kontraktif lemah- $\phi$ untuk pemetaan single valued.

Teorema 3. Misalkan $(X, p)$ adalah suatu ruang metrik parsial lengkap dan $\phi:[0, \infty) \rightarrow:[0, \infty)$ adalah fungsi kontinu tak turun dengan $\phi(t)<t$ untuk setiap $t>0$. Jika $T: X \rightarrow X$ adalah suatu pemetaan sedemikian sehingga

$$
p(T x, T y) \leq \phi\left(\max \left\{p(x, y), p(x, T x), p(y, T y), \frac{1}{2}[p(x, T y)+p(y, T x)]\right\}\right)
$$

untuk semua $x, y \in X$, maka $T$ mempunyai titik tetap tunggal.

Selain itu, Masiha, dkk. (2013) mengembangkan pemetaan kontraktif lemah $-\phi$ pada pemetaan single valued di ruang metrik parsial terurut dengan mendefinisikan fungsi $\phi$ sebagai berikut.

Definisi 4. Jika $\phi:[0, \infty) \rightarrow:[0, \infty)$ memenuhi

(i) 0 dan $\phi(t)>0$ untuk setiap $t>0$

(ii) $\phi$ adalah semi kontinu menurun dari kanan yaitu untuk sebarang barisan tak menaik dan tak negatif $\left\{r_{n}\right\}, \liminf _{n \rightarrow \infty} \phi\left(r_{n}\right) \geq \phi(r)$, menghasilkan $\lim _{n \rightarrow \infty} r_{n} \geq r$

(iii) Untuk sebarang barisan $\left\{r_{n}\right\}$ dengan $\lim _{n \rightarrow \infty} r_{n}=0$, terdapat $a \in(0,1)$ dan $n_{0} \in \mathbb{N}$ sedemikian sehingga $\phi\left(r_{n}\right) \geq a r_{n}$ untuk setiap $n \geq n_{0}$.

Didefinisikan $\Phi=\{\phi: \phi$ memenuhi kondisi (i)-(iii) pada Definisi 4$\}$.

Teorema 5 [Masiha, dkk. 2013] Misalkan $(X, \leq)$ adalah himpunan terurut parsial dan andaikan terdapat suatu metrik parsial $p$ pada $X$ sedemikian sehingga $(X, p)$ adalah suatu ruang metrik parsial lengkap. Andaikan $T: X \rightarrow X$ adalah pemetaan kontinu dan tak menurun sedemikian sehingga

$$
p(T x, T y) \leq p(x, y)-\phi(p(x, y))
$$


untuk semua $x, y \in X$ dan $\phi \in \Phi$. Jika terdapat suatu bilangan $x_{0} \in X$ dengan $x_{0} \leq T x_{0}$, maka terdapat $x \in X$ sedemikian sehingga $x=T x$. Selanjutnya $p(x, x)=0$.

Berdasarkan hasil pada Teorema 3 dan Teorema 5, pada makalah ini akan dikaji tentang eksistensi titik tetap pada pemetaan multivalued di ruang metrik parsial lengkap yang merupakan pemetaan kontraktif lemah.

\section{JARAK HAUSDORFF}

Misalkan $(X, d)$ adalah suatu ruang metrik. Menurut (Widder, 2009), pemetaan multivalued didefinisikan sebagai pemetaan dari $X$ ke $\wp(X)$ dan ditulis

$$
T: X \rightarrow \wp(X)
$$

dengan $\wp(X)=\{S \mid S \subset X, S \neq \emptyset\}$. Selanjutnya, (Istrătescu, 1981 dalam Widder, 2009) memberikan definisi untuk titik tetap dari pemetaan multivalued. Suatu titik $x \in X$ disebut titik tetap dari pemetaan multivalued $T: X \rightarrow \wp(X)$ jika

$$
x \in T(x)
$$

Pada makalah ini, eksistensi titik tetap pada pemetaan kontraktif lemah $-\phi$ di ruang metrik parsial lengkap untuk pemetaan multivalued akan dibuktikan menggunakan metrik atau fungsi jarak Hausdorff dalam penentuan jarak antar himpunan bagian di $\wp(X)$. Jarak Hausdorff didefinisikan sebagai berikut.

Definisi 6. [Ahmad, dkk. 2013] Misalkan $(X, d)$ adalah sebuah ruang metrik. Untuk $A, B \in \wp(X)$ dan $A, B \neq \varnothing$, jarak Hausdorff untuk setiap dua himpunan bagian $A$ dan $B$ didefinisikan sebagai berikut:

- Jika $x \in X$, jarak dari $x$ ke $B$ adalah

$$
p(x, B)=i n f_{b \in B} d(x, b)
$$

- Jarak dari $A$ ke $B$ adalah

$$
\delta_{p}(A, B)=\sup _{x \in A} p(x, B)
$$

- Jarak Hausdorff antar himpunan bagian $A$ ke $B$ adalah

$$
H(A, B)=\max \{\delta(A, B), \delta(B, A)\}=\max \left\{\sup _{x \in A} d(x, B), \sup _{x \in B} d(x, A)\right\} .
$$


Selain itu, eksistensi titik tetap pada makalah ini juga akan dibuktikan menggunakan proposisi berikut.

Proposisi 7. [Ahmad, dkk. 2013] Jika $A$ dan $B$ adalah himpunan bagian tak kosong, tertutup dan terbatas $(C B)$ dari ruang metrik partial $(X, p)$ dan $0<h \in$ $\mathbb{R}$, maka untuk setiap $a \in A$, terdapat $b \in B$ sedemikian sehingga $p(a, b) \leq$ $H_{p}(A, B)+h$.

Pada Proposisi 7, pemetaan $H_{p}: C B^{p}(X) \times C B^{p}(X) \rightarrow[0,+\infty)$ adalah metrik parsial Hausdorff yang diinduksi oleh $p$.

\section{HASIL PENELITIAN}

Eksistensi titik tetap pada pemetaan kontraktif lemah $-\phi$ di ruang metrik parsial lengkap untuk pemetaan multivalued disajikan pada teorema berikut.

Teorema 7. Misalkan $(X, p)$ adalah suatu ruang metrik parsial lengkap dan $\phi:[0, \infty) \rightarrow:[0, \infty)$ adalah fungsi kontinu tak turun yang memenuhi $\phi(t)<t$ untuk setiap $t>0$. Jika $T: X \rightarrow C B(X)$ adalah suatu pemetaan sedemikian sehingga

$H_{p}(T x, T y) \leq \phi\left(\max \left\{p(x, y), p(x, T x), p(y, T y), \frac{1}{2}[p(x, T y)+p(y, T x)]\right\}\right)$

untuk semua $x, y \in X$, maka $T$ mempunyai titik tetap tunggal.

Bukti. Dari kondisi pada $\phi$, jelaslah bahwa $\lim _{n \rightarrow \infty} \phi^{n}(t)=0$ untuk $t>0$. Misalkan $x_{0} \in X$ adalah sebarang titik. Didefinisikan sebuah barisan $\left\{x_{n}\right\}$ di $X$ dengan $x_{n} \in T x_{n-1}$ untuk $n=1,2, \ldots$ Andaikan $x_{n_{0}}=x_{n_{0}+1}$ untuk $n_{0}=$ $0,1,2, \ldots$. , maka jelas bahwa $x_{n_{0}}$ adalah suatu titik tetap dari T. Sekarang, asumsikan $x_{n} \neq x_{n+1}$ untuk semua $n$.

Langkah 1. Akan ditunjukkan bahwa $\lim _{n \rightarrow \infty} p^{s}\left(x_{n}, x_{n+1}\right)=0$.

Dari pertidaksamaan (1) dan Proposisi 6, diperoleh $p\left(x_{n+1}, x_{n}\right) \leq \mathcal{H}_{p}\left(T x_{n}, T x_{n-1}\right)+h$ 


$$
\begin{aligned}
& \leq \phi\left(\operatorname { m a x } \left\{p\left(x_{n}, x_{n-1}\right), p\left(x_{n}, T x_{n}\right), p\left(x_{n-1}, T x_{n-1}\right), \frac{1}{2}\left[p\left(x_{n}, T x_{n-1}\right)\right.\right.\right. \\
& \left.\left.\quad+p\left(x_{n-1}, T x_{n}\right)\right\}\right) \\
& \leq \phi\left(\max \left\{p\left(x_{n}, x_{n-1}\right), p\left(x_{n}, x_{n+1}\right), p\left(x_{n-1}, x_{n}\right), \frac{1}{2}\left[0+p\left(x_{n-1}, x_{n+1}\right)\right\}\right)\right. \\
& =\phi\left(\max \left\{p\left(x_{n}, x_{n-1}\right), p\left(x_{n}, x_{n+1}\right)\right\}\right) \\
& =\phi\left(p\left(x_{n}, x_{n-1}\right)\right)
\end{aligned}
$$

Andaikan $p\left(x_{n}, x_{n+1}\right)>p\left(x_{n}, x_{n-1}\right)$, maka

$$
p\left(x_{n}, x_{n+1}\right) \leq \phi\left(p\left(x_{n}, x_{n-1}\right)\right)
$$

Ini mengakibatkan $p\left(x_{n}, x_{n+1}\right)=0$. Karena $0=p\left(x_{n}, x_{n+1}\right)>p\left(x_{n}, x_{n-1}\right)$, maka hal ini adalah kontradikasi. Dengan demikian, haruslah

$$
\max \left\{p\left(x_{n}, x_{n-1}\right), p\left(x_{n}, x_{n+1}\right)\right\}=p\left(x_{n}, x_{n-1}\right) .
$$

Jadi, ketaksaman (2) menjadi

$$
p\left(x_{n+1}, x_{n}\right) \leq \phi\left(p\left(x_{n}, x_{n-1}\right)\right)
$$

untuk semua $n$. Jika persamaan (3) dilanjutkan, maka diperoleh

$$
p\left(x_{n+1}, x_{n}\right) \leq \phi^{n}\left(p\left(x_{1}, x_{0}\right)\right)
$$

Dengan kata lain, karena

$$
\max \left\{p\left(x_{n}, x_{n}\right), p\left(x_{n+1}, x_{n+1}\right)\right\} \leq p\left(x_{n}, x_{n+1}\right),
$$

maka dari (4) diperoleh

$$
\max \left\{p\left(x_{n}, x_{n}\right), p\left(x_{n+1}, x_{n+1}\right)\right\} \leq \phi^{n}\left(p\left(x_{1}, x_{0}\right)\right) .
$$

Jadi,

$$
\begin{aligned}
p^{s}\left(x_{n}, x_{n+1}\right) & =2 p\left(x_{n}, x_{n+1}\right)-p\left(x_{n}, x_{n}\right)-p\left(x_{n+1}, x_{n+1}\right) \\
& \leq 2 p\left(x_{n}, x_{n+1}\right)+p\left(x_{n}, x_{n}\right)+p\left(x_{n+1}, x_{n+1}\right) \\
& \leq 4 \phi^{n}\left(p\left(x_{1}, x_{0}\right)\right)
\end{aligned}
$$

Ini menunjukkan bahwa $\lim _{n \rightarrow \infty} p^{s}\left(x_{n}, x_{n+1}\right)=0$.

Langkah 2. Akan ditunjukkan bahwa $\left\{x_{n}\right\}$ adalah barisan Cauchy

Diketahui bahwa,

$$
\begin{aligned}
p^{s}\left(x_{n+k}, x_{n}\right) & \leq p^{s}\left(x_{n+k}, x_{n+k-1}\right)+\cdots+p^{s}\left(x_{n+1}, x_{n}\right) \\
& \leq 4 \phi^{n+k-1}\left(p\left(x_{1}, x_{0}\right)\right)+\cdots+4 \phi^{n}\left(p\left(x_{1}, x_{0}\right)\right),
\end{aligned}
$$


Ini menunjukkan $\left\{x_{n}\right\}$ adalah barisan Cauchy pada ruang metrik $\left(X, p^{S}\right)$. Karena $(X, p)$ adalah ruang metrik parsial lengkap, maka berdasarkan Lemma 2, $\left(X, p^{s}\right)$ juga merupakan ruang metrik lengkap dan barisan $\left\{x_{n}\right\}$ konvergen di ruang metrik $\left(X, p^{s}\right)$, katakan $\lim _{n \rightarrow \infty} p^{s}\left(x_{n}, x\right)=0$. Juga dari Lemma 2, didapat

$$
p(x, x)=\lim _{n \rightarrow \infty} p\left(x_{n}, x\right)=\lim _{n, m \rightarrow \infty} p\left(x_{n}, x_{m}\right)
$$

Lebih jauh, karena $\left\{x_{n}\right\}$ adalah barisan Cauchy pada ruang metrik $\left(X, p^{s}\right)$, maka diperoleh $\lim _{n, m \rightarrow \infty} p^{s}\left(x_{n}, x_{m}\right)=0$ dan dari (5) diperoleh $\lim _{n \rightarrow \infty} p\left(x_{n}, x_{n}\right)=$ 0 . Definisi $p^{s}$ selanjutnya memberikan $\lim _{n, m \rightarrow \infty} p\left(x_{n}, x_{m}\right)=0$. Oleh karena itu, dari (5) didapatkan $p(x, x)=\lim _{n \rightarrow \infty} p\left(x_{n}, x\right)=\lim _{n, m \rightarrow \infty} p\left(x_{n}, x_{m}\right)=0$.

Langkah 3. Akan ditunjukkan $T$ mempunyai titik tetap.

Sekarang akan ditunjukkan bahwa $p(x, T x)=0$. Asumsikan hal ini tidak benar. Jadi, berdasarkan sifat metrik $p$ dan juga dari (1) didapatkan

$$
\begin{aligned}
p(x, T x) & \leq p\left(x, T x_{n}\right)+H_{p}\left(T x_{n}, T x\right)-H_{p}\left(T x_{n}, T x_{n}\right) \\
& \leq p\left(x, x_{n+1}\right)+H_{p}\left(T x_{n}, T x\right) \\
& \leq p\left(x, x_{n+1}\right)+\phi\left(\max \left\{\begin{array}{c}
p\left(x, x_{n}\right), p(x, T x), p\left(x_{n}, x_{n+1}\right), \\
\frac{1}{2}\left[p\left(x, x_{n+1}\right)+p(x, T x)\right.
\end{array}\right\}\right) \\
& \leq p\left(x, x_{n+1}\right)+\phi\left(\max \left\{\begin{array}{c}
\left.\frac{1}{2}\left[p\left(x, x_{n+1}\right)+p\left(x_{n}, x\right)+p(x, T x)-p(x, x)\right\}\right) \\
\end{array}\right\} p\left(x, x_{n+1}\right)+\phi\left(\max \left\{\frac{1}{2}\left[p\left(x, x_{n}\right), p(x, T x), p\left(x_{n+1}, x_{n+1}\right)+p\left(x_{n}, x\right)+p(x, T x)\right\}\right)\right.\right.
\end{aligned}
$$

Untuk $n \rightarrow \infty$, dengan menggunakan sifat kontinuitas dari $\phi$ diperoleh

$$
p(x, T x) \leq \phi(p(x, T x)) .
$$

Hal ini merupakan kontradiksi. Oleh karena itu, $p(x, T x)=0$. Karena $T x \in$ $C B(X)$, maka didapat $x \in T x$. Jadi, $x$ merupakan titik tetap dari pemetaan multivalued di ruang metrik $(X, p)$.

Selanjutnya, akan ditunjukkan titik tetap $x \in T x$ adalah tunggal. Asumsikan $u \neq x$ adalah titik tetap yang lain dari $T$, maka $u \in T u$. Dari (1), diperoleh

$$
\begin{aligned}
p(x, u) & \leq \mathcal{H}_{p}(T x, T u)+h \\
& \leq \phi\left(\max \left\{p(x, u), p(x, T x), p(u, T u), \frac{1}{2}[p(x, T u)+p(u, T x)\}\right)\right.
\end{aligned}
$$




$$
\begin{aligned}
& \leq \phi\left(\max \left\{p(x, u), 0,0, \frac{1}{2}[p(x, u)+p(u, x)\}\right)\right. \\
& =\phi(p(x, u))
\end{aligned}
$$

Hal ini merupakan kontradiksi terhadap sifat fungsi $\phi$, yaitu $\phi(p(x, u))<p(x, u)$. Dengan demikian, diperoleh $p(x, u)=0$, yang mengakibatkan $x=u$. Ini memberikan kesimpulan bahwa titik tetapnya bersifat tunggal.

\section{KESIMPULAN DAN SARAN}

\subsection{Kesimpulan}

Sifat ketunggalan titik tetap pada pemetaan kontraktif lemah juga berlaku pada pemetaan multivalued di ruang metrik parsial lengkap. Dalam membuktikan hal ini, perhitungan jarak antar dua himpunan dilakukan dengan menggunakan metrik Hausdorff karena metrik Hausdorff pada himpunan tertutup dan terbatas memenuhi sifat metrik parsial.

\subsection{Saran}

Pada pemetaan kontraktif lemah untuk singlevalued terdapat keterkaitan antara kondisi kontraktif lemah dengan kondisi kontraktif Matthew. Oleh karena itu, penelitian lanjut dapat dilakukan untuk mengetahui keterkaitan antara kondisi kontraktif lemah dan kondisi kontraktif Matthew untuk pemetaan multivalued.

\section{DAFTAR PUSTAKA}

Ahmad, J., Azam, A. dan Arshad, M., Fixed Points of Multivalued Mappings in Partial Metric Spaces, Fixed Point Theory and Applications, 2013, 316.

Altun, I., Sola, F. dan Simsek, H., Generalized contraction on Partial Metric Space, Topology and its Applications, 157(18) (2010), 2778-2785.

Bukatin, M. dan Matthews, S., Partial Metric Space, Publ. Int. Math,, 2009, 708718.

Gangopadhyay, M., Saha, M. dan Baisnab, A.P., Some Fixed Point Theorems in Partial Metric Spaces, TWMS Journal. App. Eng. Math, 3(2) (2013), 206213. 
Kir, M. dan Kiziltunc, H., Generalized Fixed Point Theorems in Partial Metric Spaces, European Journal of Pure and Applied Mathematics, 9(4) (2016), 443-451.

Masiha, H.P., Sabetghadam, F. dan Shahzad, N., Fixed Point Theorems in Partial Metric Spaces with an Application, Faculty of Science and Mathematics, University of Nis, Serbia, 2013.

Widder, A., Fixed Point Theorems For Set-Valued Map, Institute for Analysis and Scientific of Technology, 2009. 
